\title{
A Review Toward Internet Crime Evaluation
}

\author{
Deepa Patil ${ }^{1 *}$, Naeem $\mathbf{N}^{2}$, Sunil $S_{G^{3}}$ \\ ${ }^{1}$ CS Department Awuv Vijayapur, India \\ ${ }^{2}$ CS Department Awuv Vijayapur, India \\ ${ }^{3}$ CS Department Awuv Vijayapur, India
}

Available online at: www.isroset.org

Received: 11/May/2018, Revised: 23/May/2018, Accepted: 10/Jun/2018, Online: 30/Jun/ 2018

\begin{abstract}
The idea of guilty party profiling in computer related wrongdoing is in its earliest stages. Essentially no exploration exists that relates guilty party profiling unequivocally to digital violations or digital hoodlums. However it can't be denied that, given the expansiveness of potential suspects in a digital occasion, some strategy for diminishing that number to a reasonable level took after by the capacity to distinguish a modest number of trustworthy suspects is extremely alluring. Today, much digital wrongdoing is dealt with by the criminal equity framework as unique instances of physical wrongdoing. There is little contention, in any case, that there are parts of PC related wrongdoings and the offenders who execute them that are special to the virtual, as opposed to the physical world. The examination portrayed in this paper looks to set up criteria for dissecting digital wrongdoings and hoodlums in the clear, unambiguous setting of the virtual world. The creators have conjectured four general classes of PC related wrongdoing: 1) robbery, 2) framework assault, 3) individual and 4) psychological warfare. This paper talks about a particular part of the individual class of digital wrongdoing: digital stalking. The four sub-types talked about are the consequence of many years of observational application involving a large number of cases in the physical world. They have demonstrated dependable in examination of vicious violations, for example, assault and kill. A basic reason in the momentum look into is use of the sub-types in digital examination. This is a "Explore in-advance" paper, exhibiting a theory that will be tried exactly in the following period of the exploration. Nonetheless, we give a model case which we delineate the potential utilization of the profiling strategies introduced.
\end{abstract}

Keywords - internet crime, power assertive,typology,subtypes,cyber stalking

\section{INTRODUCTION}

HE Web is a general empowering agent. It not just gives open doors for research and business to this point inaccessible to the vast majority, it likewise gives a way to criminal action conceivably unrivaled in the pre-Web age. Since the Web gives the dream - and, once in a while, the truth - of namelessness, those wishing to seek after criminal action discover the Web a sheltered and prolific ground for their endeavors. One of those exercises, empowered by the Web and the current condition of the Internet (some of the time alluded to as "web 2.0"), is cyber stalking. There has been some discourse in the writing of cyber stalking as an expansion of physical stalking [2][6][7], be that as it may, McFarlane and Bocij [8] oppose this idea. The separation of cyber stalking as a one of a kind demonstration, yet sharing a portion of the attributes of physical stalking, is an essential point for giving a typology of cyber stalkers that can be utilized solidly by agents. Our situation in such manner underpins McFarlane and Bocij, notwithstanding, we discover their typologies constrained with respect to their utilization as an investigative instrument. With minimal solid data on stalking in the physical world and even less in the virtual world [5], the thought of creating reasonable typologies for cyber stalkers has not been all around created. McFarlane and Bocij [8] have proposed a cyber stalker typology - pernicious, formed, cozy and group - however this typology does little to separate individual cyber stalkers with the end goal that examiners can center around one of a kind speculates in view of their individual practices. It is that concentration with which this paper bargains.

\section{RELATED WORK}

There are a few hypotheses from the more natural wrongdoing of physical stalking that can be considered for incorporation in the domain of cyber stalking. One such hypothesis is standard action hypothesis (Rodent) [3][4]. Basically, Rodent says that wrongdoing is unavoidable (inspired guilty parties) and that if an appropriate target is unprotected (nonattendance of a fit gatekeeper), he or she is a potential casualty. The simple in the virtual world says that if an objective frequents open locales and isn't secured, he or she may succumb to some type of digital evil. Rodent in the internet is most effectively outlined by the weakness of numerous PC clients to malware (malevolent programming, 
for example, infections) and hacking dangers. For instance, Web surfers who visit erotic entertainment locales will probably confront security dangers, for example, an infection or session capturing (34.2\% of free smut destinations and $11.4 \%$ of for-pay destinations are influenced) than the individuals who don't visit those locales [9]. Likewise, one may estimate that people who visit long range interpersonal communication destinations, for example, Facebook or utilize items, for example, AOL Moment Detachment vigorously are putting themselves in an unsafe position in respect to cyber stalking. The way to maintaining a strategic distance from trade off under the Rodent is ensuring oneself. On account of malware security, this comprises of staying away from perilous sites and guaranteeing that hostile to malware assurance is introduced and forward. On account of cyber stalking, security may comprise of restricting the measure of individual data the individual makes accessible on the web. Holt and Bossler [10] report some achievement in applying Rodent to cyber harassment and cyber stalking. While Rodent offers a decent structure for helping potential focuses of cyber stalking abstain from getting to be casualties, it doesn't offer the examiner much help with recognizing a cyber stalker. McFarlane and Bocij's typology is constrained in that it centers around wide portrayals of cyber stalkers. These wide portrayals don't offer the granular differentiators that examiners require to lead a tenable, prosecutable cyber stalking examination. The four kinds portrayed by these creators put cyber stalkers in gatherings, however don't separate satisfactorily at the individual level nor are they combined with an investigative approach that makes them valuable to examiners. As clinical portrayals they do, in any case, have justify if taken in the organization of other clinical analyses. Too, the exact research detailed in [8] and [14] are very valuable in understanding the wrongdoing of cyber stalking, in any event in the UK where a great part of the exploration was led. The most encouraging typology originates from Keppel and Walter [1]. This typology, the way things are, is centered around sexual related kill. Be that as it may, we have discovered that it can be stretched out neatly to give a helpful typology to surveying cybercrimes and profiling digital guilty parties, for this situation, cyber stalkers. An essential qualification must be made between a mental appraisal and a criminological evaluation. A mental evaluation centers upon the clinical viewpoints (e.g., analysis and treatment) of the person. A criminological appraisal centers upon wrongdoing and criminal acts. For the reasons for wrongdoing appraisal, we look at the criminological - and for this situation, the digital criminological - continuum. The examiner applies the subsorts to the wrongdoing and after that works outward towards the individual suspects. The Keppel/Walter Sub-Sorts Working off of early research by Groth and Birnbaum [11] and resulting work by Hazelwood and Burgess detailed in an early release of [12], Keppel and Walter stretched out the typology of attackers to incorporate assault/kill [1]. The extensibility of this typology, as appeared by Hazelwood, Walter, et al, proposes that it is a perfect possibility for looking at digital stalking. It is on these sub-types that we base our examination into profiling of digital wrongdoings and hoodlums. The profiling of cyber stalkers is an initial phase toward that path. The sub-types depicted in [1] incorporate Power Self-assured, Power Consolation, Outrage Retaliatory, and Outrage Excitation. Quickly, this paper portrays these subtypes in the accompanying segment in spite of the fact that we are intrigued fundamentally in Power Self-assured and Power Consolation when we examine cyber stalking

\section{Methodology}

\section{A. Power Confident}

The power decisive (Dad) performing artist is engaged upon power and animosity and utilizations them to control the casualty. Mighty terrorizing and direct utilization of power are signs of the power decisive subtype. We expand this into the virtual world by including, for instance, the measurements of boasting about the on-screen character's stalking achievements in such mysterious settings as open gatherings, interpersonal interaction locales and unknown dialog gatherings, and capability in PC innovation. The Dad on-screen character has a tendency to be sorted out and in the digital world might be a software engineer or favor him or herself to be a super programmer. The power emphatic onscreen character must keep up his or her power and does it through expanding the level of haughtiness and terrorizing that can be seen in messages and different postings. The performer is egocentric and applies his or her sense of self to look after strength. In the Dad cyber stalker, the level of control accessible in the virtual world may not be sufficient for the stalker to trust that he or she is keeping up control over the casualty and, in this way, may rise to a physical gathering in reality. That gathering can bring about assault or assault kill.

\section{B. Power Consolation}

The power consolation (PR) performing artist is like the Dad on-screen character with some essential contrasts. The huge distinction is the effect of imagination on this performing artist. By dream, we mean the distinction amongst reality and what the performing artist needs as well as accepts to be genuine by means of supernatural thinking1. In the composed performer, this may play out as big name stalking, for instance, where the on-screen character trusts that the big name is enamored with him or her. Conversely, the confused on-screen character may focus on either side of his or her age gathering or, if inside a similar age range, he or she may center upon the tested physically, rationally, or credulous - 
for the investigation and abuse of energy. The PR performer needs to strengthen his or her perspective of him-or her-self and this occasionally displays as a basic absence of selfassurance and refinement. This may, however, be a piece of the PR performing artist's dream. The performer will endeavor to draw in the casualty in his or her dream and will build animosity more respectably than the Dad on-screen character. Nonetheless, when that does not work, the PR conduct may raise to Dad. The PR performer is less sorted out than the Dad and may leave more pieces of information that empower the following of the cyber trail all the more effectively. In the digital world, the PR on-screen character may utilize a doctored photograph and make a persona that he or she accepts will be appealing to the casualty. In spite of the fact that the on-screen character may present as being low on self-assurance, he or she will endeavor to seem certain and when the online association stops to fulfill the performing artist's dream, he or she may endeavor to heighten to a gathering in the

\section{Outrage Retaliatory}

The outrage retaliatory (AR) on-screen character is brimming with threatening vibe and will act that fierceness out against the particular source or, if the source is inaccessible, an emblematic focus on that speaks to the genuine reason for genuine or envisioned wrongs. While the objective of the wrath might be at least one people, the genuine reason might be at least one people or an association. AR performing artists in the internet don't as a rule raise to gatherings in the physical world and, truth be told, AR conduct is rarer than Dad or PR conduct in the online world. D. Outrage Excitation Outrage excitation (AE) performing artists are perverted and concentrate their exercises on threatening the casualty. The level of hostility increments until the point when the performing artist accomplishes the demolition of the objective. Since AE activities are hard to accomplish in the internet, the $\mathrm{AE}$ compose cyber stalker is extremely uncommon.

\section{Utilizing THE SUB-Sorts IN The internet}

The sub-types are connected particularly in criminal profiling and profiling stalkers in the internet is no exemption. Basically, the profiler starts by describing the wrongdoing in light of the confirmation accessible. The proof, for this situation, incorporates interviews with casualties, criminological examination of the casualty computer(s), Web access Supplier (ISP) logs, subpoena comes about because of ISPs, long range informal communication destinations and other online entrances that were associated with getting to the casualty. These outcomes in a profile of the wrongdoing that the agent can coordinate with the profiles of suspects. Since most stalkers in the physical world are known by their casualties, we may expect that the same is valid in the online world [13]. This ends up being the situation, yet the elements of that nature are fairly unique in the internet. In the online world, the adjust of previous huge others versus new "companions" met online in visit rooms, informal communication destinations, and so on is tilted towards those met on the web. Nonetheless, Bocij does not concur totally [14]. He reports that there is dependably [his emphasis] some sort of connection between the disconnected physical world stalker and his casualty." Bocij puts forth this expression as a differentiator between physical world and digital world stalkers. He battles that cyber stalkers don't generally know their casualties. This does not consider the broad utilization of informal communities in the internet where associations can turn out to be extremely individual despite the fact that the on-screen characters have never met face to face. For a PR cyber stalker, such restricted contact online can form into a dream that outcomes in forceful cyber stalking and once in a while, a heightening to a genuine physical gathering, frequently with genuine results. Factually most physical stalkers are men and most casualties are ladies [13]. There is little proof to question that adjust in the internet, albeit approving it is one of the objectives of the experimental segment of this exploration.

A.Examination Investigation of a cyber stalking occurrence should start with a reasonable comprehension of the occasions making up the episode. That incorporates point by point interviews with the casualty and a nitty gritty measurable investigation of the casualty's PC. Dad cyber stalkers are probably going to have a direct to abnormal state of PC ability and that will be obvious in anonymization of messages and different messages or direct access, assuming any, to the casualty's PC. Regularly the casualty will have erased hostile messages and different postings. Those should be recuperated forensically from the casualty's PC. Examination of the exercises of the cyber stalker through reproduction of correspondences with the casualty is the following stage. That imaginable will require subpoenas ISPs, entryway administrators, email administrations, and person to person communication locales. There is a high probability that some type of false name will have been utilized by the cyber stalker. Cross that false name to a genuine individual. That chain of proof - additionally called a cyber trail - might be a many-headed hydra driving in an assortment of bearings. A solitary cyber stalker may utilize numerous assumed names. Once the profile of the wrongdoing is finished it must be coordinated with that of the individual cyber stalker. The cyber stalker's moniker is then followed to a genuine individual and that individual is profiled utilizing a similar sub-types. That might be finished by performing broad inquiries on the Web to discover different cases of the speculates exercises or by examination 
of the known qualities of the recognized person. On the off chance that the speculates profile coordinates the profile of the occasion, the last advance is to break down the appropriate cyber trail to build up that there was, truth be told, contact with the casualty. While cyber stalking reaches out into this present reality, confirm assembled through this procedure can be of material help to examiners. Since one of the fundamental contrasts amongst physical and cyber stalking is the effect of topography - physical stalkers must be in the geographic region of their casualties, while cyber stalkers don't should be [13] - an imperative part of cyber stalking-turned-physical is geology. Note that a PR cyber stalker can heighten to Dad, yet going the other way is farfetched. The PR cyber stalker at first may adopt a to some degree gentler strategy towards satisfying his or her dream with the casualty than will a Dad cyber stalker. At the point when that does not create comes about, the cyber stalker may turn out to be more forceful and the attributes of the Dad go to the fore. On the off chance that a cyber stalker begins as Dad and progresses toward becoming PR, the specialist ought to be suspicious that he or she is being gamed by the subject. It is likely that the performing artist is Dad. One more essential point merits specifying. It is less regular for a performer to present as just a single kind than to exhibit some adjust of more than one. For instance, a Dad cyber stalker may have a touch of AR that tends to present as outrage towards the casualty. Be that as it may, the agent ought to be ready when creating intention to the overwhelming kind, which for this situation is Dad. The thought process is power and control over the casualty. The outrage may essentially be a appearance of the cyber stalker's have to control and is to a greater degree an instrument than a total typology.

\section{CASE EXAMPLE}

In the mid 1990s, one of the creators took a shot at a stalking situation where the casualty was a lady in the HR bureau of a medium-measure organization. She had been utilized already by another association and had been compelled to flame a man who therefore stalked her physically for quite a while. Subsequently, she cleared out the association in light of the fact that there appeared to be nothing that the association would do to secure her and the performing artist was an exceptionally vicious man. Quite a while had passed when the cyber stalking and provocation (digital badgering is a superset of cyber stalking for the motivations behind this illustration) started, however the bugging messages demonstrated definite information of the prior occasions. She normally accepted that it was a similar individual. After finishing an examination - which did exclude profiling - the on-screen character was observed to be a co-representative of the casualty. The casualty had been enlisted, to a limited extent, to control the conduct of other HR representatives, particularly in their selecting practices, and this specific worker disdained that control. She, subsequently, utilized cyber stalking to restore her control and power inside the office. A. Examination This was a great Dad cyber stalking. The on-screen character utilized email with anonymization to stalk the casualty and expanded the level of animosity to the point where the casualty started to fear for her life and thought about leaving the organizations utilize. This, obviously, was the goal of the cyber stalker. In her every day work, the performing artist could be viewed as Dad. She was controlling, somewhat of an unstable presence and endeavored to threaten colleagues and chiefs into giving her a chance to have her direction and exercise her obligations as and when she wished. Coordinating the conspicuous Dad qualities with the Dad idea of the associate would have indicated the performing artist instantly, yet tragically, digital profiling systems were not grown at that point even as they are not presently. There is the conspicuous contention that there is no assurance, given the size and dispersal of the online world, that the cyber stalker would be anyplace close to the physical closeness to the casualty or that there would be an association that would help examiners in recognizing the suspect. In any case, there are various devices today that can help in that distinguishing proof. At the season of the occurrence, those apparatuses did not, obviously, exist. That being stated, the factual association amongst assailants and casualties in the physical world may have a tendency to be reproduced in the internet [13]. On the off chance that that is the situation, as it was for the situation case, distinguishing suspects is commonsense. Moreover, following the cyber trail of the stalker can enable examiners to distinguish the speculate paying little mind to where he or she may be geologically found with respect to the casualty. This case shows the potential advantages of creating digital profiling. Setting up parallels between the physical and online universes is a target of future periods of

This exploration. Once the profiles of the occurrence and the potential suspects had been finished, following the cyber trail would have driven unavoidably to the performing artist. The performer was heightening her cyber stalking into the physical world by debilitating the casualty's young child raising the level hostility - and setting nails under the child's auto tires. Despite the fact that the cyber stalker herself did not have a sufficiently high ability level to play out the anonymizing of the stalking messages, her better half did and in evident Dad form, the performer got her significant other to make and send the messages for her. Including somebody with more prominent PC aptitudes through terrorizing isn't phenomenal with Dad cyber stalkers. 


\section{CONCLUSION AND FUTURE SCOPE}

Future Exploration As this paper appears, stretching out the sub-sorts to the on-line world is doable. Following stages in this examination incorporate performing exact research utilizing genuine cases, analyzing parallels between the on the web and physical universes, and stretching out the subsorts to alternate classes of digital wrongdoing. Wrongdoing evaluation in the physical world incorporates inspecting exercises amid the wrongdoing and additionally prewrongdoing and post-wrongdoing exercises. These are lined up with the sub-sorts to comprehend the idea of the wrongdoing and afterward connected to suspects. Now, examiners create profiles of the presumes utilizing the subsorts and match them to the wrongdoing evaluation. Regularly this examination will point to at least one suitable suspect. Future research will test this approach in the advanced world.

The advancement of a solid technique for wrong doing appraisal and wrongdoer profiling for digital violations is both alluring and, in the present online condition, vital. Sadly, most endeavors at this so far have been clinically engaged inside the mental area instead of applying the criminological continuum and being expected for the specialist of digital episodes. Surveying cyber stalking episodes and profiling cyber stalkers utilizing the Keppel/Walter sub-types is a magnificent place to begin building up this investigative capacity in light of the fact that there is a nearby connection between's physical stalking and cyber stalking. The creators speculate, be that as it may, that the sub-sorts can be reached out to all types of digital wrongdoing: burglary, framework assault, individual, and psychological oppression.

\section{REFERENCES}

[1] R. D. Keppel, and R. Walter, "Profiling killers: a revised classification model for understanding sexual murder," International Journal of Offender Therapy and Comparitive Criminology, vol. 43, no. 4, pp. 417437, 1999.

[2] M. L. Pittaro, "Cyber stalking: an analysis of online harassment and intimidation," International Journal of Cyber Criminology, vol. 1, no. 2, pp. 180-197, 2007.

[3] L. E. Cohen, and M. Felson, "Social change and crime rate trends: a routine activity approach," American Sociological Review, vol. 44, no. 4, pp. 588-608, 1979.

[4] E. E. Mustain, and R. Tewksbury, "A routine activity theory explanation for women's stalking victimization,". Violence Against Women, vol. 5, no. 1, pp. 43-62, 1999.

[5] L. McFarlane, and P. Bocij, "Cyber stalking: defining the invasion of cyberspace," Forensic Update, vol. 1, no. 72, pp. 18-22, 2003.

[6] E. Ogilvie, "Cyberstalking," in Trends and Issues in Crime and Criminal Justice, no. 166. Canberra, Australia: Australian Institute of Criminology, 2000, pp. 1-6.

[7] A. W. Burgess, and T. Baker, "Cyberstalking," in Stalking and psychosexual obsession:Psychological perspectives for prevention, policing and treatment, J. Boon, and L. Sheridan, Eds. Chichester, UK: Wiley, 2002, ch. 12.

[8] L. McFarlane, and P. Bocij. (2003, September). An exploration of predatory behaviour in cyberspace: Towards a typology of cyberstalkers. First Monday [Online]. 8(9). [Cited: January 3, 2011] Available: http://firstmonday.org/htbin/cgiwrap/bin/ojs/index.php/fm/article/v iew/1 076/996.

[9] G. Wondracek, C. Platzer, E. Kirda, and C. Kruegel. "Is the Internet for porn? An insight into the online adult industry," in Proc. 9th Workshop on the Economics of Information Security, Harvard University, Cambridge, Massachusetts, USA, 2010, pp. 1-14.

[10] T. J. Holt, and A. M. Bossler, "Examining the applicability of lifestyleroutine activities theory for cybercrime victimization," Deviant Behavior, vol. 30, no. 1, pp. 1-25, 2009.

[11] N. A. Groth, and H. J. Birnbaum, Men Who Rape: The Psychology of the Offender. New York, NY: Plenum Press, 1979.

[12] R. R. Hazelwood, and A. W. Burgess, Practical Aspects of Rape Investigation (4th ed.). Boca Raton, FL : CRC Press, 2009.

[13] United States. Attorney General to the Vice President. 1999 Report on Cyberstalking: A New Challenge for Law Enforcement and Industry. Washington DC : United States Department of Justice, 1999.

[14] P. Bocij, Cyberstalking - Harassment in the Internet Age and How to Protect Your Family. Westport, CT: Praeger Publishers, 2004. ASIA. 